\title{
RESEARCH
}

Open Access

\section{Birth, stillbirth and death registration data completeness, quality and utility in population-based surveys: EN-INDEPTH study}

Simon Kasasa ${ }^{1,2,3^{*}+}$, Davis Natukwatsa ${ }^{1,3+}$, Edward Galiwango ${ }^{1,3}$, Tryphena Nareeba ${ }^{1,3}$, Collins Gyezaho ${ }^{1,3}$, Ane Baerent Fisker ${ }^{4,5,6}$, Mezgebu Yitayal Mengistu ${ }^{7,8}$, Francis Dzabeng ${ }^{9}$, M. Moinuddin Haider ${ }^{10}$, Judith Yargawa ${ }^{11}$, Joseph Akuze ${ }^{11,12,13}$, Angela Baschieri ${ }^{11}$, Claudia Cappa ${ }^{14}$, Debra Jackson 11,14,15, Joy E. Lawn ${ }^{11}$, Hannah Blencowe ${ }^{11 \dagger}$, Dan Kajungu ${ }^{1,3+}$ and the Every Newborn-INDEPTH Study Collaborative Group

\begin{abstract}
Background: Birth registration is a child's first right. Registration of live births, stillbirths and deaths is foundational for national planning. Completeness of birth registration for live births in low- and middle-income countries is measured through population-based surveys which do not currently include completeness of stillbirth or death registration.

Methods: The EN-INDEPTH population-based survey of women of reproductive age was undertaken in five Health and Demographic Surveillance System sites in Bangladesh, Ethiopia, Ghana, Guinea-Bissau and Uganda (2017-2018). In four African sites, we included new/modified questions regarding registration for 1177 stillbirths and 11,881 livebirths (1333 neonatal deaths and 10,548 surviving the neonatal period). Questions were evaluated for completeness of responses, data quality, time to administer and estimates of registration completeness using descriptive statistics. Timing of birth registration, factors associated with non-registration and reported barriers were assessed using descriptive statistics and logistic regression.

(Continued on next page)
\end{abstract}

\footnotetext{
* Correspondence: skasasa@musph.ac.ug

${ }^{\dagger}$ Simon Kasasa and Davis Natukwatsa are joint first authors. Hannah Blencowe and Dan Kajungu are joint senior authors

${ }^{1}$ IgangaMayuge Health and Demographic Surveillance System, Makerere University Centre for Health and Population Research, Iganga, Uganda

2Department of Epidemiology and Biostatistics, Makerere University School of Public Health, Kampala, Uganda

Full list of author information is available at the end of the article
}

C C The Author(s). 2021 Open Access This article is licensed under a Creative Commons Attribution 4.0 International License, which permits use, sharing, adaptation, distribution and reproduction in any medium or format, as long as you give appropriate credit to the original author(s) and the source, provide a link to the Creative Commons licence, and indicate if changes were made. The images or other third party material in this article are included in the article's Creative Commons licence, unless indicated otherwise in a credit line to the material. If material is not included in the article's Creative Commons licence and your intended use is not permitted by statutory regulation or exceeds the permitted use, you will need to obtain permission directly from the copyright holder. To view a copy of this licence, visit http://creativecommons.org/licenses/by/4.0/ The Creative Commons Public Domain Dedication waiver (http://creativecommons.org/publicdomain/zero/1.0/) applies to the data made available in this article, unless otherwise stated in a credit line to the data. 
(Continued from previous page)

Results: Almost all women, irrespective of their baby's survival, responded to registration questions, taking an average of $<1$ min. Reported completeness of birth registration was 30.7\% (6.1-53.5\%) for babies surviving the neonatal period, compared to $1.7 \%$ for neonatal deaths (0.4-5.7\%). Women were able to report age at birth registration for $93.6 \%$ of babies. Non-registration of babies surviving the neonatal period was significantly higher for home-born children (aOR 1.43 (95\% Cl 1.27-1.60)) and in Dabat (Ethiopia) (aOR 4.11 (95\% Cl 3.37-5.01)). Other socio-demographic factors associated with non-registration included younger age of mother, more prior births, little or no education, and lower socio-economic status. Neonatal death registration questions were feasible (100\% women responded; only $1 \%$ did not know), revealing extremely low completeness with only $1.2 \%$ of neonatal deaths reported as registered. Despite $>70 \%$ of stillbirths occurring in facilities, only $2.5 \%$ were reported as registered.

Conclusions: Questions on birth, stillbirth and death registration were feasible in a household survey. Completeness of birth registration is low in all four sites, but stillbirth and neonatal death registration was very low. Closing the registration gap amongst facility births could increase registration of both livebirths and facility deaths, including stillbirths, but will require co-ordination between civil registration systems and the often over-stretched health sector. Investment and innovation is required to capture birth and especially deaths in both facility and community systems.

Keywords: Neonatal death, Stillbirth, Survey, Birth certificates, Birth registration, Death registration, Vital statistics

\section{Key findings}

\section{What is new}

- What was known already: Birth registration is a marker of civil rights and is receiving increased investment. Household surveys, including Demographic and Health Surveys (DHS) and UNICEF's Multiple Indicator Cluster Surveys (MICS), are important sources of populationlevel information on completeness of birth registration but the data quality is unknown. Stillbirth registration or neonatal/child death registration are not included in DHS or MICS surveys.

- What was done: As part of the EN-INDEPTH survey, we evaluated new and modified questions on birth, stillbirth and death registration for 13 , 058 births (1177 stillbirths, 1333 neonatal deaths, 10,548 live births surviving the neonatal period) in four African Health and Demographic Surveillance Systems sites.

\section{What was found?}

- Completeness of responses: Questions were almost universally answered (>99\% responses complete, $<5 \%$ do not know responses) in an average of $<1 \mathrm{~min}$ in all sites.

- Completeness of registration: Birth registration completeness was $30.7 \%$ overall for children surviving the neonatal period (with variation across the four study sites, being lowest in Dabat, Ethiopia), compared to just $1.7 \%$ for babies who died in the first 28 days. Most infants were reported to be registered in the first 3 months of life. Completeness of neonatal death and stillbirth registration was very low with only $1.2 \%$ of babies who died in the neonatal period and $2.5 \%$ of stillbirths reported as registered.

- Data quality: Women reported age at birth registration for 93.6\% of registered children surviving the neonatal period, with a plausible distribution of age at registration, but some heaping at 6-month intervals. - Data utility: Inequities in birth registrations are clear in this study population with children more likely to be unregistered if they were born at home, had younger or less educated mothers and lower socioeconomic status. Common reasons for non-registration amongst 7312 unregistered children surviving the neonatal period were complexity of registration process (36\%), financial barriers (28\%) and distance (16\%).

\section{What next in measurement and research?}

- Measurement improvement now: Reliable measures in surveys are crucial to track birth registration completeness and identify who is left behind in this marker for child rights, e.g., by sex, maternal education, or socio-economic status. Given that around $80 \%$ of the world's births are now in facilities, facilitating facility-based registration for these babies would increase birth and stillbirth registration completeness and

\section{Key findings (Continued)}

also allow tracking through routine facility and vital statistics data, instead of relying only on 5-yearly surveys.

- Research needed: Death registration for stillbirths and neonatal deaths are extremely low. Further research is needed to identify solutions to address barriers to death registration in facility and community systems.

\section{Background}

Despite the right to an identity being enshrined in the UN convention on the rights of the child [1] as well as in other major human rights instruments, globally millions are born and die each year without ever being officially recorded in a national civil registration system $[2,3]$. Failure to be registered is associated with poverty, vulnerability to rights violations, marginalisation and exclusion from health, social, economic and political development [3]. Accurate information on live births, stillbirths and deaths is required for public health tracking improvements in maternal-child health and progress towards Sustainable Development Goals (SDG) 3,11 and $16[4,5]$. In theory, civil registration and vital statistics (CRVS) systems are the preferred mechanism for measuring all births (both live and stillbirths) and deaths; however, unfortunately CRVS in the countries with the highest mortality burden have the lowest completeness of birth, stillbirth and death registration [6].

Investment in CRVS systems in many low- and middle-income countries (LMICs) is increasing [6]. Particular attention has been placed on birth registration, which is the term used to refer to registration of live births, leading to substantial improvements over the past decade, with three out of four children under the age of five worldwide now registered with civil authorities [3, 6-9]. The majority (87\%) of the estimated 166 million unregistered children under- 5 years are in southern Asia 
and sub-Saharan Africa and wide socio-economic inequalities and gaps between urban and rural areas remain $[3,10]$.

Death registration systems lag behind birth registration [11]. Only 60 countries worldwide are currently assessed as having good quality overall child death registration data from vital statistics, with few outside developed regions [12]. The status for information on neonatal deaths is even worse, with fewer than $5 \%$ of all neonatal deaths worldwide estimated to receive a death certificate [12]. Information on stillbirths is collected within a 'stillbirth or fetal death register' within the CRVS system, and whilst not currently systematically collated at a global level, is likely to be worse than for neonatal deaths [13].

Estimates of the completeness of registration data in LMICs rely on nationally representative household surveys such as demographic and health surveys (DHS) and multiple indicator cluster surveys (MICS) [14]. In the registration of vital events, first the event is registered with the civil authorities, and then a certificate is issued. In many settings certificates are not issued for stillbirths, and even for other events, financial and other logistically barriers result in not every registered event receiving a certificate. In DHS, there is a single birth registration question in the household roster asking if children 0-4 years who are currently alive have a birth certificate, with a probe question regarding birth registration with the civil authorities asked only for children without a birth certificate. In MICS similar questions are asked regarding surviving children under five in the household. Whilst completeness of birth certification is critical to protecting the rights of surviving children, not including children who died prior to the survey visit might have overestimated the completeness of birth registration. Neither platform includes questions on birth or death registration for children who have died or questions on registration for stillbirths. Failure to include such questions is potentially a missed opportunity within vital statistics to track completeness of registration for stillbirths, neonatal and child deaths. However, the feasibility of collecting information on birth or death registration for children who have died, or for stillbirths is not known.

This paper is part of a series of papers from the Every Newborn-International Network for the Demographic Evaluation of Populations and their Health (EN-INDEPTH) study in five health and demographic surveillance system (HDSS) sites in Africa and Asia. This paper aims to improve understanding of the measurement of birth, stillbirth and death registration in population-based household surveys through the following objectives:

1. Survey question performance: Evaluate new and modified questions on birth, stillbirth and neonatal death registration addressed to women in a population-based survey, including completeness of responses and time implications.

2. Data utility: Assess the information obtained through the survey regarding birth, stillbirth and neonatal death registration including estimates of completeness and timing of registration, factors associated with nonregistration and reported barriers to registration.

\section{Methods}

\section{EN-INDEPTH study design and setting}

The EN-INDEPTH study was a cross-sectional multisite study conducted between July 2017 and August 2018, including a survey of 69,176 women aged 15-49 years undertaken in five HDSS sites: Bandim in GuineaBissau, Dabat in Ethiopia, IgangaMayuge in Uganda, Matlab in Bangladesh and Kintampo in Ghana (Additional file 1 provides background details of these sites). The protocol and main study paper are published elsewhere and provide further details $[11,15]$. The primary objective of the study was to randomly compare two methods of retrospective recording of pregnancy outcomes in surveys: full birth history with additional questions on pregnancy losses $(\mathrm{FBH}+)$ and full pregnancy history $(\mathrm{FPH})$ as detailed elsewhere $[11,15]$.

Both woman and interviewer data were collected on Android tablets using the Survey Solutions data collection and management system [16]. Interviewers were recruited locally and were familiar with the culture and dialect of the study area. Following completion of data collection, data from the five HDSS sites were anonymised by local HDSS scientists, encrypted and then shared [11].

The EN-INDEPTH study also investigated the performance of existing, modified and new survey questions to capture additional information on pregnancies and birth. This included a sub-sample of survey respondents in the four African sites being asked to provide answers to questions on birth, and where relevant death, registration for their most recent live birth and all neonatal deaths and stillbirths since 1st January 2012 (Additional file 2). Whilst possession of a birth certificate is critical for ensuring the rights of surviving children, in these analyses we are especially interested in whether babies were registered and thus counted in vital statistics to inform public health action. These four countries differ in terms of legal frameworks and operational systems for CRVS (Table 1).

\section{Methods by objective \\ Objective 1: Evaluate survey question performance}

Information on birth, stillbirth and death registration was assessed in the survey using the questions shown in Table 2. These questions included standard MICS questions and additional questions on time from birth to registration and for babies surviving the neonatal period reasons for non-registration. Each question was assessed for 
Table 1 Comparison of legal framework and operational systems for birth and stillbirth registration

\begin{tabular}{|c|c|c|c|c|}
\hline & Ghana & Guinea-Bissau & Ethiopia & Uganda \\
\hline $\begin{array}{l}\text { Legislation } \\
\text { status }\end{array}$ & $\begin{array}{l}\text { Registration of Births, Deaths } \\
\text { Act 1965. Not linked to services }\end{array}$ & $\begin{array}{l}1967 \text { Civil code of registry. } \\
\text { Birth certificate required for } \\
\text { school enrolment, ID, } \\
\text { Passport }\end{array}$ & $\begin{array}{l}\text { Proclamations } 2012 \text { and } 2017 . \\
\text { First permanent, compulsory } \\
\text { and universal nationwide } \\
\text { system launched in August } \\
2016\end{array}$ & $\begin{array}{l}2015 \text { Act amended. Certificate } \\
\text { issued in } 2 \text { days and required } \\
\text { for school enrolment, national } \\
\text { ID, bank account, passport, } \\
\text { driving licence, public service } \\
\text { job, joining police and } \\
\text { military forces }\end{array}$ \\
\hline $\begin{array}{l}\text { Responsibility } \\
\text { to notify birth }\end{array}$ & $\begin{array}{l}\text { Parents, guardian, occupier } \\
\text { of premises where birth } \\
\text { took place }\end{array}$ & $\begin{array}{l}\text { Parents, doctor, family } \\
\text { member, village chief }\end{array}$ & Parents, doctor, family member & $\begin{array}{l}\text { Hospital, sub-county chief, } \\
\text { parents/guardian }\end{array}$ \\
\hline $\begin{array}{l}\text { Documents } \\
\text { required for } \\
\text { birth } \\
\text { registration }\end{array}$ & Biological parents' ID & $\begin{array}{l}\text { IDs of parents, presence } \\
\text { of parents, birth notification } \\
\text { from hospital, } \\
\text { immunization card to verify } \\
\text { DOB, Child name }\end{array}$ & $\begin{array}{l}\text { Parents IDs, parents physical } \\
\text { presence (unless for justified } \\
\text { reason), Child name, DOB }\end{array}$ & $\begin{array}{l}\text { Biological parents' ID, parents } \\
\text { birth certificates, child names, } \\
\text { place of birth notification }\end{array}$ \\
\hline $\begin{array}{l}\text { Charge for } \\
\text { birth } \\
\text { registration }\end{array}$ & Nil & $\begin{array}{l}\text { Free for 0-7-year old. No } \\
\text { fee for abridged certificate }\end{array}$ & Nil & $\mathrm{Nil}$ \\
\hline $\begin{array}{l}\text { Charge for } \\
\text { birth } \\
\text { certificate }\end{array}$ & Nil & Fee detailed birth certificate & Charged & 5000 shillings $^{a}$ \\
\hline $\begin{array}{l}\text { Legal } \\
\text { required } \\
\text { time-frame } \\
\text { for registration }\end{array}$ & 1 year from birth & 30 days & 90 days & No limit \\
\hline $\begin{array}{l}\text { Late } \\
\text { registration } \\
\text { penalty }\end{array}$ & Yes, after 1 year. Fine not shown & $\begin{array}{l}\text { Yes, } 8-13 \text { years and higher } \\
\text { for } 14 \text { years and more }\end{array}$ & $\begin{array}{l}\text { Fine } 5000 \text { Ethiopian Birr }{ }^{b} \text { or } \\
\text { imprisonment up to } 6 \text { months }\end{array}$ & None for nationals \\
\hline $\begin{array}{l}\text { Methods for } \\
\text { birth } \\
\text { registration }\end{array}$ & Electronic & Manual & ---- & $\begin{array}{l}\text { Manual + electronic } \\
\text { (computer/tabs) }\end{array}$ \\
\hline $\begin{array}{l}\text { Enforcement } \\
\text { of law }\end{array}$ & ---- & ---- & ---- & $\begin{array}{l}\text { Implemented, but challenged } \\
\text { with late reporting, corruption, } \\
\text { lack of national internet } \\
\text { coverage data transition }\end{array}$ \\
\hline $\begin{array}{l}\text { Current } \\
\text { initiatives to } \\
\text { increase birth } \\
\text { registration }\end{array}$ & $\begin{array}{l}\text { From } 2010 \text { to } 2014 \text { HDSS staff } \\
\text { notified births to district levels and } \\
\text { encouraged mothers to register } \\
\text { births during } 1 \text { st month of life. } \\
\text { Funding for this initiative ended in } \\
2014 \text {. }\end{array}$ & $\begin{array}{l}\text { UNICEF sponsors radio } \\
\text { spot messages encouraging } \\
\text { birth registration; however, } \\
\text { there are no direct } \\
\text { incentives to register. }\end{array}$ & $\begin{array}{l}\text { Mass media and health worker } \\
\text { campaigns to increase } \\
\text { community awareness. No } \\
\text { direct incentives to encourage } \\
\text { birth registration }\end{array}$ & $\begin{array}{l}\text { Some recent innovation using } \\
\text { app-based Mobile Vital records } \\
\text { System to register births in } \\
\text { community and some facilities. }\end{array}$ \\
\hline $\begin{array}{l}\text { Stillbirth } \\
\text { registration }\end{array}$ & $\begin{array}{l}\text { Registration of Births and Deaths } \\
\text { Act } 1965 \text { requires registration of all } \\
\text { fetal deaths. There is a separate } \\
\text { register for stillborn children. }\end{array}$ & $\begin{array}{l}\text { Fetal deaths (stillbirths) } \\
\text { are not registered. }\end{array}$ & $\begin{array}{l}\text { Fetal deaths (stillbirths) are not } \\
\text { registered }\end{array}$ & $\begin{array}{l}\text { Fetal deaths (stillbirths) are } \\
\text { not registered }\end{array}$ \\
\hline
\end{tabular}

Data source: UNICEF [38]; $D O B$ date of birth

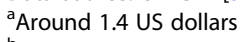

${ }^{\mathrm{b}}$ Around 150 US dollars

completeness and 'don't know' responses including any variations by maternal and child characteristics including survival status using descriptive statistics. Numerical answers were assessed for heaping using graphical plots and heaping index.

Time taken to complete the birth and death registration section was assessed using the EN-INDEPTH survey paradata. Paradata were collected by the app during the survey and provide detailed records of data entry and corrections made for each question, stored as time-stamped 'events'.
Time taken for each question was defined as the time interval between the time-stamp for the question(s) under study and the previous question. Missing data and responses that took $30 \mathrm{~min}$ or more were excluded.

\section{Objective 2: Assess utility of survey data}

Completeness of birth registration and mean time from birth to registration were calculated overall and by HDSS site for babies who died before the 28th day after birth (neonatal deaths) and those surviving the neonatal 
Table 2 Birth and death registration questions in Demographic and Health, and Multiple Indicator Cluster and EN-INDEPTH surveys

\begin{tabular}{|c|c|c|c|}
\hline & $\begin{array}{l}\text { Placement in } \\
\text { questionnaire }\end{array}$ & Target & Coding of responses \\
\hline \multicolumn{4}{|c|}{ DHS-7 and DHS-8 standard birth and death registration questions } \\
\hline $\begin{array}{l}\text { Does (name) have a birth certificate? If no, probe: } \\
\text { Has (name)'s birth ever been registered with the } \\
\text { civil authority? }\end{array}$ & Household roster & $0-4$ year olds currently alive & $\begin{array}{l}1=\text { has certificate, } 2=\text { registered } \\
3=\text { neither, } 4=\text { don't know }\end{array}$ \\
\hline Question(s) on death registration & None & - & - \\
\hline \multicolumn{4}{|l|}{ MICS6 birth and death registration questions } \\
\hline $\begin{array}{l}\text { Does (name) have a birth certificate? If yes, ask: } \\
\text { May I see it? }\end{array}$ & $\begin{array}{l}\text { Questionnaire for children } \\
\text { under five administered } \\
\text { to mothers/ caretaker }\end{array}$ & 0-4 year olds currently alive & $\begin{array}{l}1=\text { yes, seen; } 2 \text { = yes, not seen; } \\
3=\text { no; } 4=\text { don't know }\end{array}$ \\
\hline $\begin{array}{l}\text { If no or don't know to above question: Has } \\
\text { (name)'s birth been registered with the civil } \\
\text { authorities? }\end{array}$ & $\begin{array}{l}\text { Questionnaire for children } \\
\text { under five administered } \\
\text { to mothers/ caretaker }\end{array}$ & 0-4 year olds currently alive & $1=$ yes, $2=$ no, 3 = don't know \\
\hline $\begin{array}{l}\text { If no or don't know to above question: 'Do you } \\
\text { know how to register (name)'s birth?' }\end{array}$ & $\begin{array}{l}\text { Questionnaire for children } \\
\text { under five administered } \\
\text { to mothers/ caretaker }\end{array}$ & 0-4 year olds currently alive & $1=$ yes, 2 = no \\
\hline Question(s) on death registration & None & - & - \\
\hline \multicolumn{4}{|c|}{ EN-INDEPTH survey birth and death registration questions } \\
\hline $\begin{array}{l}\text { Does (name/this baby) have a birth certificate? }{ }^{\text {a If }} \\
\text { yes, ask: May I see it? }\end{array}$ & $\begin{array}{l}\text { Section } 4 \text { of the women's } \\
\text { questionnaire }\end{array}$ & $\begin{array}{l}\text { Subset of livebirths and all } \\
\text { stillbirths since 1st January } 2012\end{array}$ & $\begin{array}{l}1=\text { yes, seen; } 2=\text { yes, not seen; } \\
3=\text { no; } 4=\text { don't know }\end{array}$ \\
\hline $\begin{array}{l}\text { Has (name/this baby)'s birth been registered with } \\
\text { the civil authorities? }\end{array}$ & $\begin{array}{l}\text { Section } 4 \text { of the women's } \\
\text { questionnaire }\end{array}$ & $\begin{array}{l}\text { Livebirths and stillbirths in last } 5 \\
\text { years whose mother's answered } \\
\text { 'No' or 'Don't know' to previous } \\
\text { question }\end{array}$ & $1=$ yes, $2=$ no, 3 = don't know \\
\hline $\begin{array}{l}\text { At which age was (name/this baby) } \\
\text { registered? }\end{array}$ & $\begin{array}{l}\text { Section } 4 \text { of the women's } \\
\text { questionnaire }\end{array}$ & $\begin{array}{l}\text { Livebirths and stillbirths in last } \\
5 \text { years }\end{array}$ & $\begin{array}{l}1=\text { weeks if less than } 4 \text { weeks, } \\
2=\text { months if less than } 2 \text { years, } \\
3=\text { years if } 2 \text { years or more, } \\
4=\text { don't know }\end{array}$ \\
\hline $\begin{array}{l}\text { Specify number of weeks, months or years } \\
\text { as appropriate }\end{array}$ & $\begin{array}{l}\text { Section } 4 \text { of the women's } \\
\text { questionnaire }\end{array}$ & $\begin{array}{l}\text { Livebirths and stillbirths in last } \\
5 \text { years }\end{array}$ & Integer \\
\hline $\begin{array}{l}\text { I am interested in knowing about the main } \\
\text { reasons why you have not registered (name). I } \\
\text { will now read some possible reasons. Please let } \\
\text { me know if any apply: } \\
\text { (i) Birth registration is not a legal requirement. } \\
\text { (ii) There is not enough money to pay the cost } \\
\text { of registering (name). } \\
\text { (iii) The distance to the registration centre is far. } \\
\text { (iv) The registration process is too complicated } \\
\text { to understand. } \\
\text { (v) I am unable to produce the full set of } \\
\text { documents required to register (name). } \\
\text { (vi) The father of (name) is required to be } \\
\text { present but he is unable or unwilling to } \\
\text { attend. } \\
\text { (vii) The name of the child is required but it } \\
\text { has not yet been given by the family. } \\
\text { (viii) Are there other reasons why you did not } \\
\text { register (name) that have not already } \\
\text { been mentioned? }\end{array}$ & $\begin{array}{l}\text { Section } 4 \text { of the women's } \\
\text { questionnaire }\end{array}$ & $\begin{array}{l}\text { Livebirths in last } 5 \text { years } \\
\text { surviving the neonatal period }\end{array}$ & $\begin{array}{l}\text { For each category: } 1=\text { yes, } \\
2=\text { no; plus free text box } \\
\text { to specify for 'other reasons' }\end{array}$ \\
\hline $\begin{array}{l}\text { Does (name/this baby) have a death certificate? If } \\
\text { yes, ask: 'May I see it?' }\end{array}$ & $\begin{array}{l}\text { Section } 4 \text { of the women's } \\
\text { questionnaire }\end{array}$ & $\begin{array}{l}\text { Neonatal deaths and stillbirths } \\
\text { in last } 5 \text { years only }\end{array}$ & $\begin{array}{l}1=\text { yes, seen; } 2=\text { yes, not seen; } \\
3=\text { no; } 4=\text { don't know }\end{array}$ \\
\hline
\end{tabular}

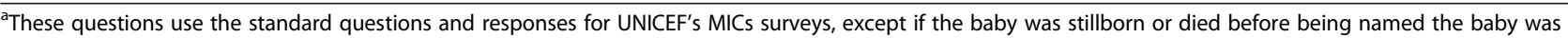
referred to as 'this baby'. A positive response to either of these questions was taken to indicate that birth registration had occurred. 
period separately. As specific questions regarding stillbirth registration were not asked, babies who were stillborn (stillbirths) were classified as registered if the mother reported that the baby was registered through either the birth or the death registration questions.

Reported reasons for non-registration of children surviving the neonatal period are presented graphically using descriptive statistics. Factors associated with nonregistration of these children were explored using logistic regression, with registration status as the dependent variable. A gap analysis comparing the coverage of facility births to completeness of birth, stillbirth and neonatal death registration was undertaken to examine potential missed opportunities for registration for facility births.

All data management and quantitative analyses were undertaken using Stata 15.1. Results are reported in accordance with STROBE Statement checklists for crosssectional studies [17] (Additional file 3).

\section{Results}

\section{Overall}

Information on birth and death registration was collected for 13,058 babies and children born to 12,462 surveyed women: Bandim (2065 women), Dabat (3606), Iganga (2254) and Kintampo (4537). These included 1177 stillborn and 11,881 liveborn babies, of whom 1333 died in the neonatal period and 10,548 survived to the 28th day of life (Fig. 1). Survey respondents differed across HDSS sites with regards to age, parity, education and place of birth. Most births took place in health facilities (63.3\%); however, in Dabat HDSS, more than half $(57.9 \%)$ of the births took place outside a health facility (Additional file 4).

\section{Objective 1: Evaluate survey question performance}

Responses to birth and death registration questions were recorded for all women.

A response of 'don't know' for 'Does (name) have a birth certificate?' was low overall (1.6\% of responses for children surviving the neonatal period, $1.9 \%$ for neonatal deaths and $3.7 \%$ for stillbirths) (Tables 3 and 4B). The additional probe question 'Has (name)'s birth been registered with the civil authorities?' resulted in a 4percentage point increase in the estimated proportion of babies registered for children surviving the neonatal period and 0.5-percentage point increase for stillbirths

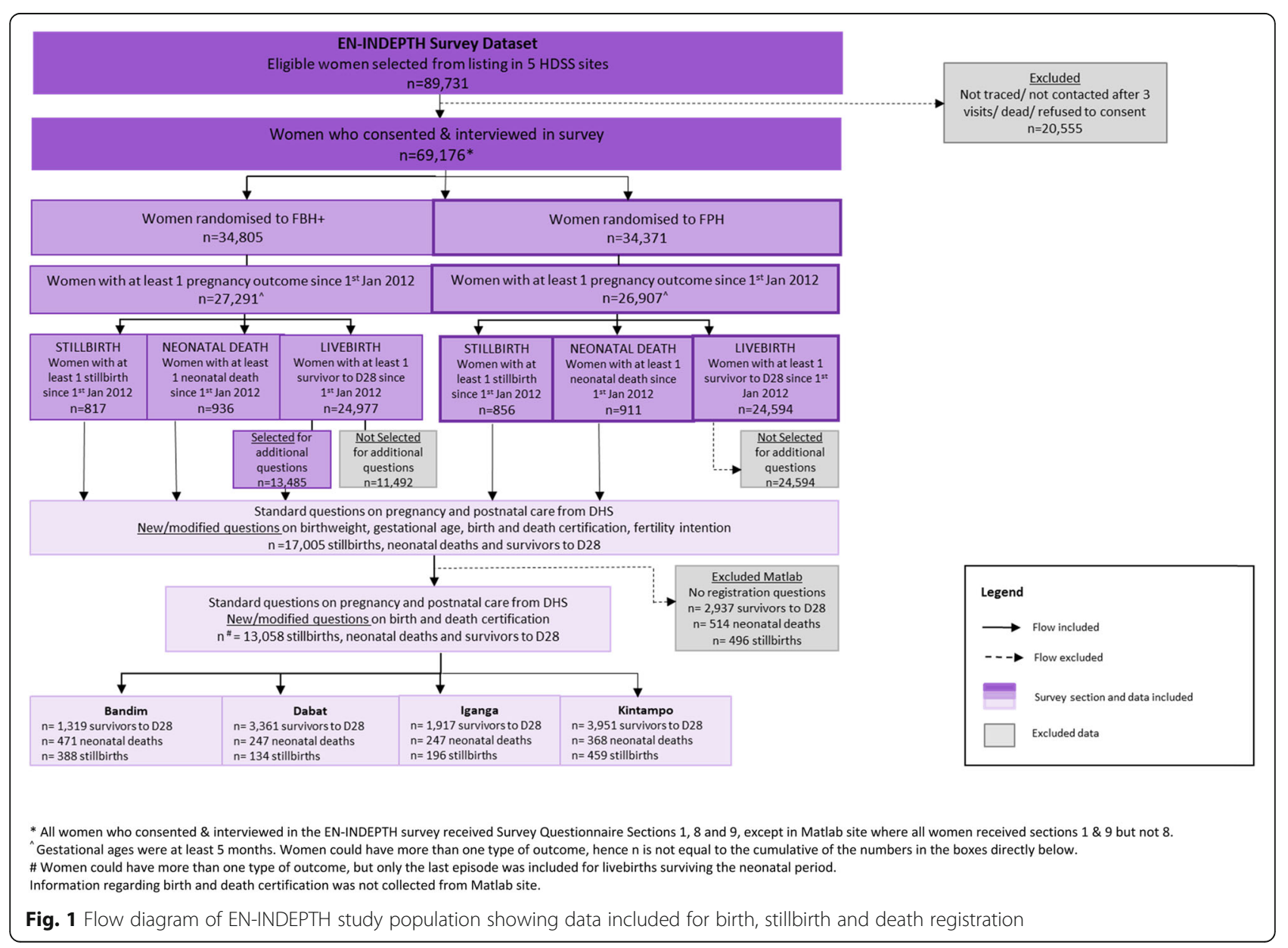


Table 3 Summary of birth registration question responses for livebirths by child's sex and HDSS site

\begin{tabular}{|c|c|c|c|c|c|c|c|}
\hline & \multirow{2}{*}{$\begin{array}{l}\text { Number of } \\
\text { live births } \\
\text { (n) }\end{array}$} & \multicolumn{4}{|c|}{ Registration with civil authorities (\%) } & \multirow{2}{*}{$\begin{array}{l}\% \text { registered } \\
\text { with civil } \\
\text { authorities }\end{array}$} & \multirow{2}{*}{$\begin{array}{l}\% \text { of children registered } \\
\text { for whom time from birth } \\
\text { to registration was reported }\end{array}$} \\
\hline & & $\begin{array}{l}\text { Registered and } \\
\text { have birth } \\
\text { certificate }\end{array}$ & $\begin{array}{l}\text { Registered but } \\
\text { don't have birth } \\
\text { certificate }\end{array}$ & $\begin{array}{l}\text { Don't know } \\
\text { whether } \\
\text { registered }\end{array}$ & $\begin{array}{l}\text { Didn't } \\
\text { register }\end{array}$ & & \\
\hline \multicolumn{8}{|c|}{ Children surviving the neonatal period } \\
\hline Overall & 10,548 & 26.7 & 4.0 & 1.6 & 67.7 & 30.7 & 93.6 \\
\hline \multicolumn{8}{|l|}{ Child sex } \\
\hline Female & 5,319 & 26.3 & 4.3 & 1.8 & 67.6 & 30.7 & 92.9 \\
\hline Male & 5,229 & 27.0 & 3.7 & 1.5 & 67.8 & 30.6 & 94.3 \\
\hline \multicolumn{8}{|l|}{ HDSS site } \\
\hline Bandim & 1,319 & 22.0 & 0.9 & 0.8 & 76.3 & 22.9 & 93.7 \\
\hline Dabat & 3,361 & 3.7 & 2.4 & 3.6 & 90.3 & 6.1 & 73.1 \\
\hline IgangaMayuge & 1,917 & 17.6 & 14.4 & 0.9 & 67.1 & 31.9 & 94.1 \\
\hline Kintampo & 3,951 & 52.2 & 1.3 & 0.5 & 46.0 & 53.5 & 95.4 \\
\hline \multicolumn{8}{|l|}{ Neonatal deaths } \\
\hline Overall & 1,333 & 1.3 & 0.5 & 1.9 & 96.3 & 1.7 & 82.6 \\
\hline \multicolumn{8}{|l|}{ Child sex } \\
\hline Female & 519 & 1.0 & 0.0 & 2.3 & 96.7 & 1 & 62.5 \\
\hline Male & 814 & 1.1 & 0.7 & 1.6 & 96.6 & 2.9 & 93.3 \\
\hline \multicolumn{8}{|l|}{ HDSS site } \\
\hline Bandim & 471 & 0.4 & 0.0 & 0.4 & 99.2 & 0.4 & 50 \\
\hline Dabat & 247 & 1.2 & 0.0 & 5.7 & 93.1 & 1.2 & 100 \\
\hline IgangaMayuge & 247 & 3.6 & 2.0 & 2.0 & 92.4 & 5.7 & 78.6 \\
\hline Kintampo & 368 & 0.8 & 0.3 & 1.1 & 97.8 & 1.1 & 100 \\
\hline
\end{tabular}

and neonatal deaths (Tables 3 and $4 \mathrm{~B})$. However, the increase varied by site, with a minimal effect in Bandim and Kintampo, but resulting in a more than two thirds increase in the number of children surviving the neonatal period reported to have been registered in Dabat and IgangaMayuge.

Most women were able to provide details of the time since birth to registration for their baby $(82.6 \%$ of neonatal deaths and $93.6 \%$ of children surviving the neonatal period) (Table 3). Response to this question was similar for male and female babies, but varied by HDSS sites, with over $90 \%$ reporting in three sites, and compared to fewer than two thirds in Dabat $(p<0.001)$.

Most women (>95\%) reported that they had not registered the death of their baby, with $1.2 \%$ of women with a neonatal death and $1.8 \%$ with a stillbirth responding that they did not know if the baby's stillbirth or death had been registered (Tables $4 \mathrm{~A}$ and $4 \mathrm{~B}$ ).

Reported median time from birth to registration did not vary by child's sex but did by site from just over 7.5 months in Dabat and to 1 month in IgangaMayuge. The few neonatal deaths that had their births registered were registered sooner after birth than children surviving the neonatal period (median time from birth to registration: neonatal deaths 1 month (Interquartile range (IQR), $0-3)$ ), children surviving the neonatal period 3 months (IQR, 1-6) (Additional file 4). There was some evidence of heaping at 6-monthly intervals in all sites, which was most marked at 12 months in three sites and at 18 months in Kintampo (Additional file 4).

The mean time to complete birth and death registration questions was less than $1 \mathrm{~min}$ in all sites, with $99 \%$ of respondents from each of the four sites taking less than 5 min (Additional file 4).

\section{Objective 2: Assess utility of survey data \\ Data on completeness of registration}

Overall, $30.7 \%$ of children surviving the neonatal period and $1.7 \%$ of neonatal deaths were reported to have had their births registered with the civil authorities. For children surviving the neonatal period, completeness of birth registration was the highest in Kintampo (53.5\%), compared to $6.1 \%$ in Dabat (Fig. 2). Reported completeness was similar to nationally reported completeness from recent surveys (Table 5). Reported completeness of birth registration for neonatal deaths in all sites was very low compared to completeness for children surviving the neonatal period $(p<0.001)$. 
Table 4A Summary of neonatal death registration question responses by child's sex and HDSS site

\begin{tabular}{|c|c|c|c|c|c|}
\hline & Number of deaths, $n$ & Death registered, \% & Don't know if death registered, \% & Not registered, \% & Missing, $\%$ \\
\hline Overall & 1333 & 1.2 & 1.2 & 97.4 & 0.2 \\
\hline \multicolumn{6}{|c|}{ Reported Birth registered } \\
\hline Yes & 23 & 21.7 & 4.3 & 73.9 & 0.0 \\
\hline No & 1288 & 0.9 & 1.1 & 98.1 & 0.0 \\
\hline Not known & 19 & 0.0 & 5.3 & 94.7 & 0.0 \\
\hline Missing & 3 & 0.0 & 0.0 & 0.0 & 100 \\
\hline \multicolumn{6}{|l|}{ Child sex } \\
\hline Female & 519 & 1.2 & 1.2 & 97.3 & 0.1 \\
\hline Male & 814 & 1.2 & 1.2 & 97.4 & 0.4 \\
\hline \multicolumn{6}{|l|}{ HDSS site } \\
\hline Bandim & 471 & 1.5 & 1.1 & 96.8 & 0.6 \\
\hline Dabat & 247 & 1.2 & 3.2 & 95.6 & 0.0 \\
\hline IgangaMayuge & 247 & 1.2 & 1.2 & 97.6 & 0.0 \\
\hline Kintampo & 368 & 0.8 & 0.0 & 99.2 & 0.0 \\
\hline
\end{tabular}

Fewer than $2 \%$ of neonatal deaths had their deaths registered in all sites (Table 4A, Additional file 4). 9.2\% of stillbirths were reported by their mothers to have been registered in IgangaMayuge, with fewer than $1.5 \%$ in other sites (Table 4B, Additional file 4).

\section{Age at registration}

The majority of registered surviving babies were registered during the first few months of life, with some evidence of catch up registration especially in the Dabat and Bandim sites (Fig. 3).

\section{Factors associated with non-registration}

For children surviving the neonatal period, being under 1 year of age at the time of the survey, born at home and maternal socio-demographic factors including younger age, higher parity, lower levels or no education and lower socio-economic status were associated with nonregistration in both crude and adjusted analyses. Nonregistration was not associated with the sex of the child (Additional file 4).

\section{Reasons for non-registration}

7,312 out of 10,548 (69.3\%) of women with a nonregistered child surviving the neonatal period provided information on barriers to registration. Amongst these, $36.1 \%$ of women reported that the birth registration process was too complicated to understand. Other commonly reported barriers included cost $(28.4 \%$ of respondents) and distance to a registration facility (16.1\%). Lack of the required documentation, father's support and a name for the baby were less frequently reported as barriers (Fig. 4, Additional file 4).

\section{Gap analysis}

Half of surviving babies that were born in a facility were reported to have had their births registered by the time of the survey; however, large between-site variation was observed (Fig. 5, Additional file 5). Kintampo has nearly closed the facility birth registration gap for children surviving the neonatal period with $81 \%$ of facility births registered, compared to $35 \%$ in IgangaMayuge, $31 \%$ in Bandim and just $14 \%$ in Dabat. In comparison, just $2.4 \%$ of neonatal deaths and $3.5 \%$ of stillbirths who were born in a facility were registered with the reported registration gap consistently large across all sites.

\section{Discussion}

Household surveys are an important source of population-level information on completeness of birth registration, and our study involved 13,058 births in four countries with varying contexts for registration. To our knowledge, this is the first study to assess the completeness and quality of data from existing survey questions on birth registration, and importantly to also evaluate new questions regarding registration of stillbirths and neonatal deaths. We also assessed how long the birth registration questions took to answer and explored factors associated with non-registration.

For birth registration, we found that women were able to answer, with no missing data and fewer than $5 \%$ don't know responses across all the questions asked. The time to administer these questions was short, with the full set of birth registration questions taking on average less than 1 min to complete in all sites.

Birth registration reported completeness was low at $30.7 \%$ overall for babies surviving the neonatal period (with variation across the four study sites, being lowest 


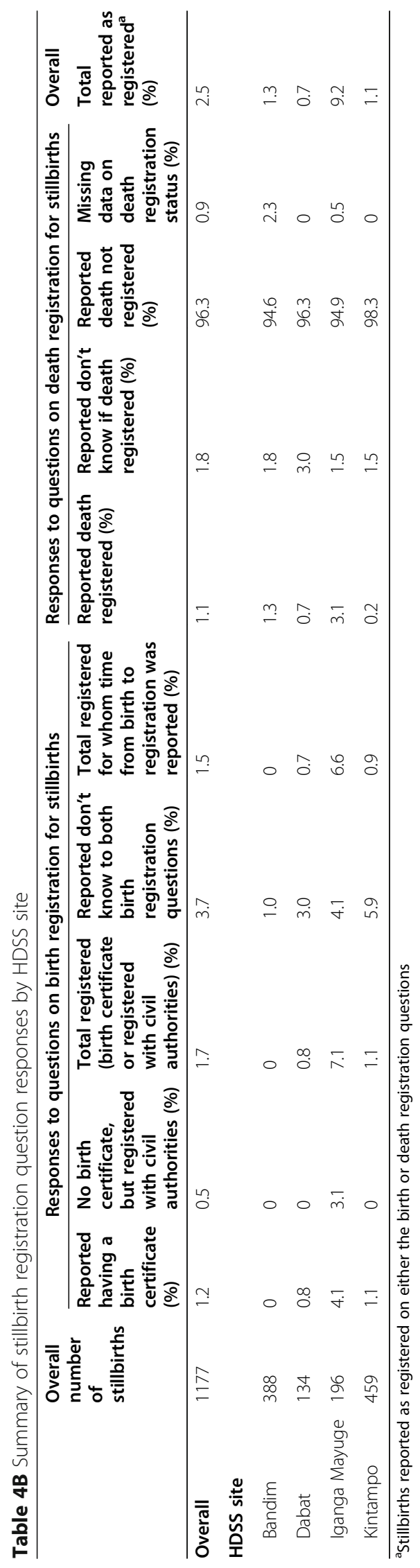




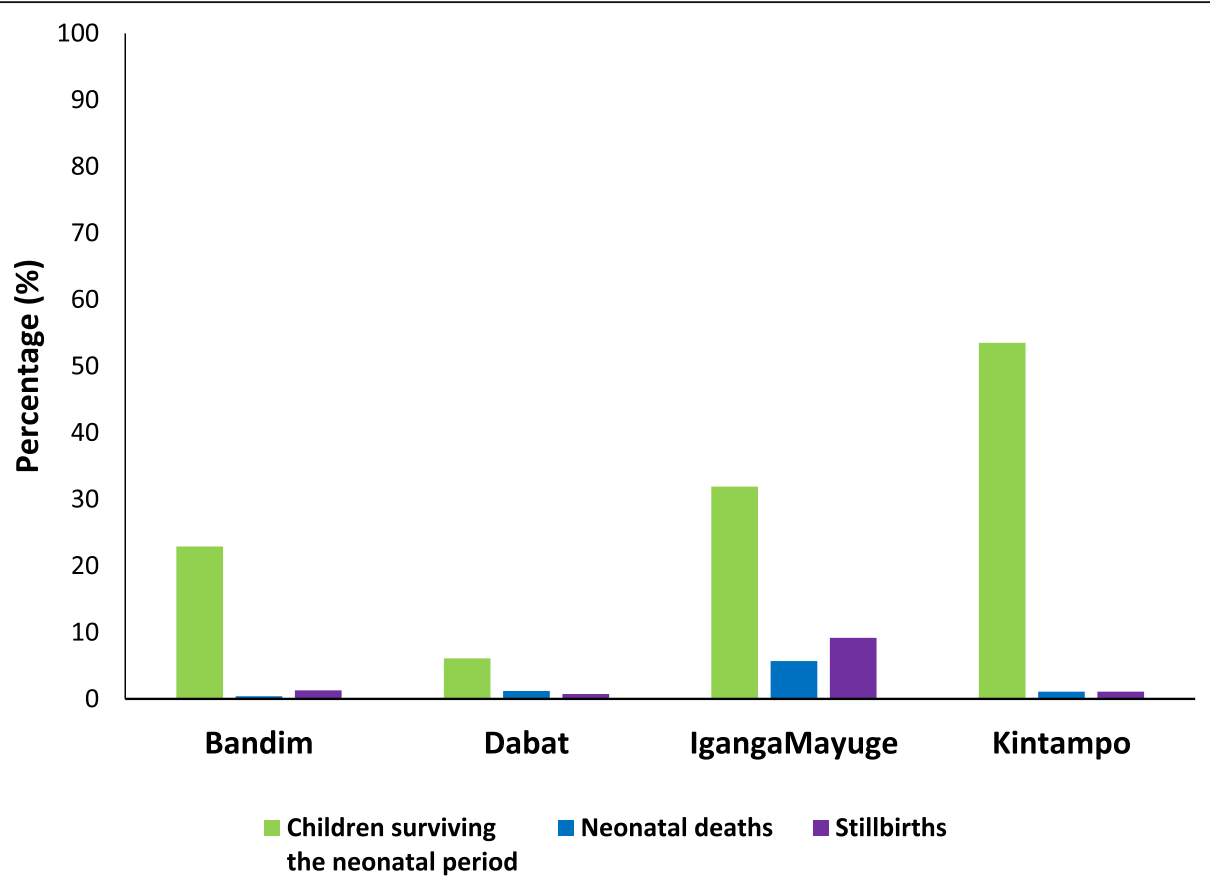

Stillbirths were classified as registered if the mother reported that either the birth, the death or both was registered.

Fig. 2 Women's report of completeness of birth registration in EN-INDEPTH survey by outcome $(n=10,548)$

in Dabat, Ethiopia), compared to birth registration for just $1.7 \%$ of neonatal deaths. Lower completeness of birth and death registration was expected in Dabat because Ethiopia's first permanent, compulsory and universal registration and certification system for vital events throughout the country is very new, only launched in August 2016 (Table 1). Therefore, national civil registration was still in the early stages during the study period [18]. Higher rates of completeness would be expected in other sites, especially in Kintampo, where an active programme was underway to increase birth registration from 2010 to 2014. For almost all registered children surviving the neonatal period, women were able to report age at registration with a plausible distribution apart from some heaping at 6-month intervals. The majority of children whose births were registered in the first 2 years of life were reported to have been registered during the first 6 months of life. In our study, very few children were registered after 2 years of age. This finding is in contrast to other studies which have found a peak in birth registrations around 5 or 6 years of age, especially where required for school entry [3, 19]. However, as the median age of the children in this study was only 25 months, our study was not designed to detect later registration peaks. Similar to previous studies, lack of birth registration was associated with home birth, lower socio-

Table 5 Completeness of birth registration for children surviving the neonatal period in EN-INDEPTH study compared to external data sources $(n=10,548)$

\begin{tabular}{llll}
\hline HDSS name & $\begin{array}{l}\text { Birth registration completeness reported in } \\
\text { EN-INDEPTH survey using single question } \\
(\mathbf{2 0 1 2 - 2 0 1 8 )}\end{array}$ & $\begin{array}{l}\text { Birth registration completeness reported in } \\
\text { EN-INDEPTH survey using two questions } \\
(\mathbf{2 0 1 2 - 2 0 1 8 )}\end{array}$ & $\begin{array}{l}\text { Birth registration } \\
\text { completeness in DHS/MICS } \\
\text { survey (national) }\end{array}$ \\
\hline $\begin{array}{l}\text { Bandim } \\
\text { (Guinea-Bissau) }\end{array}$ & $290(22.0 \%)$ & $302(22.9 \%)$ & $24 \%$ MICS 2014 \\
$\begin{array}{l}\text { Dabat } \\
\text { (Ethiopia) }\end{array}$ & $124(3.7 \%)$ & $205(6.1 \%)$ & $3 \%$ DHS 2016 \\
$\begin{array}{l}\text { lgangaMayuge } \\
\text { (Uganda) }\end{array}$ & $337(17.6 \%)$ & $612(31.9 \%)$ & $32 \%$ DHS 2016 \\
$\begin{array}{l}\text { Kintampo } \\
\text { (Ghana) }\end{array}$ & $2063(52.2 \%)$ & $2114(53.5 \%)$ & $71 \%$ DHS 2014
\end{tabular}

Data source: data.unicef.org

Estimates from the EN-INDEPTH include only children alive after the neonatal period. This will slightly overestimate population-based coverage due to very low coverage of birth certification for neonatal deaths. Estimates from standard DHS only include coverage for currently alive children in the roster, which may overestimate further coverage as child deaths at any age would be excluded. 


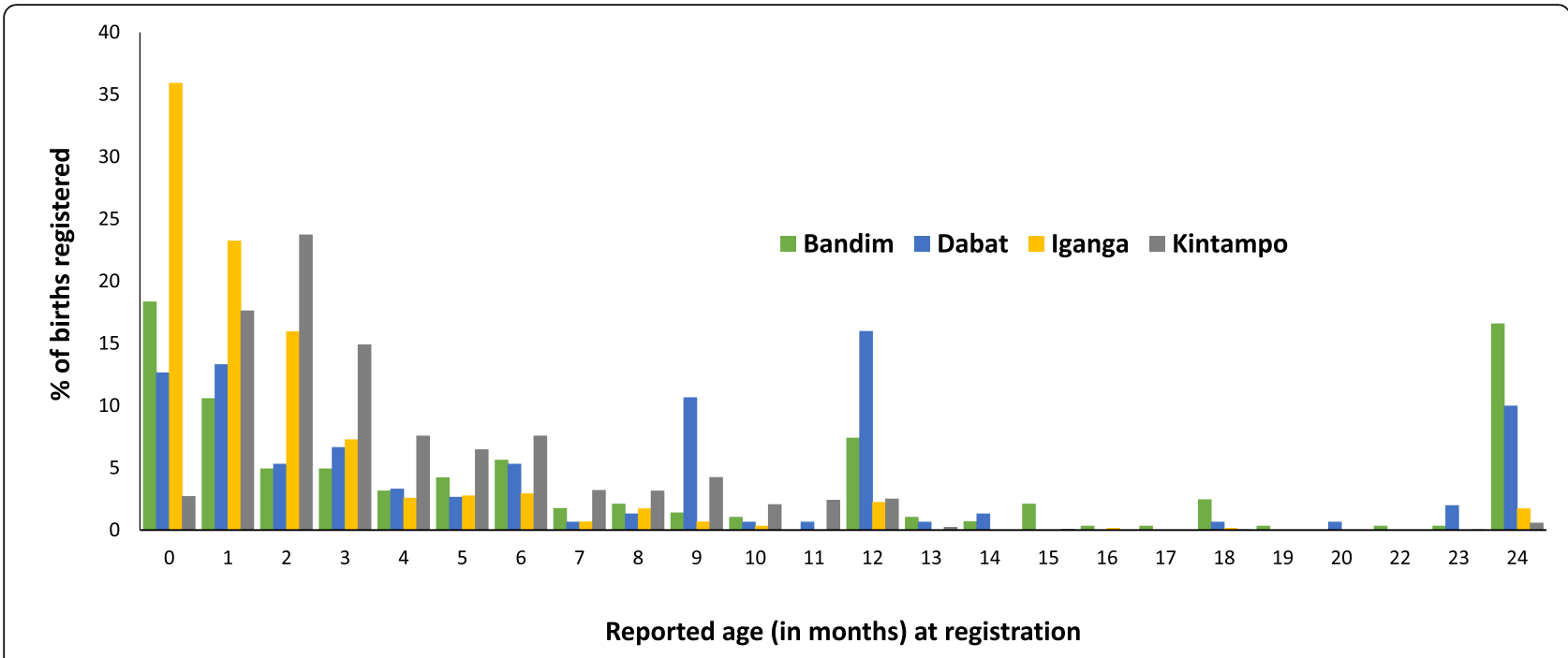

Note: Excluding children registered after 2 years of age and 5 implausible values with reported age at registration $>6$ years.

Fig. 3 Age at registration for children surviving the neonatal period registered by age 24 months $(n=2972)$

economic and educational status, but not with the sex of the child [3, 20-24].

Barriers to birth registration are asked in the MICS for 45 countries and in half of these countries, carers reported not knowing how to register the child (Table 2). However in the remaining countries, most caregivers of unregistered children seem aware of the birth registration process [3]. Our study provided more detail by asking new questions to mothers of unregistered children to elucidate if any of seven different potential reasons contributed to non- registration and found complexity of the registration process $(36 \%)$, cost $(28 \%)$ and distance to registration facility (16\%) as the commonest reported barriers. Our findings regarding knowledge of the registration process and distance are similar to a previous study in Niger [25]; however, more women in our study reported cost to be a barrier. In a previous study in urban Bandim, $42 \%$ of women reported lack of pre-requisite documents and $28 \%$ the father's absence as barriers to birth registration; these were less commonly reported as barriers in our multi-site study [11].

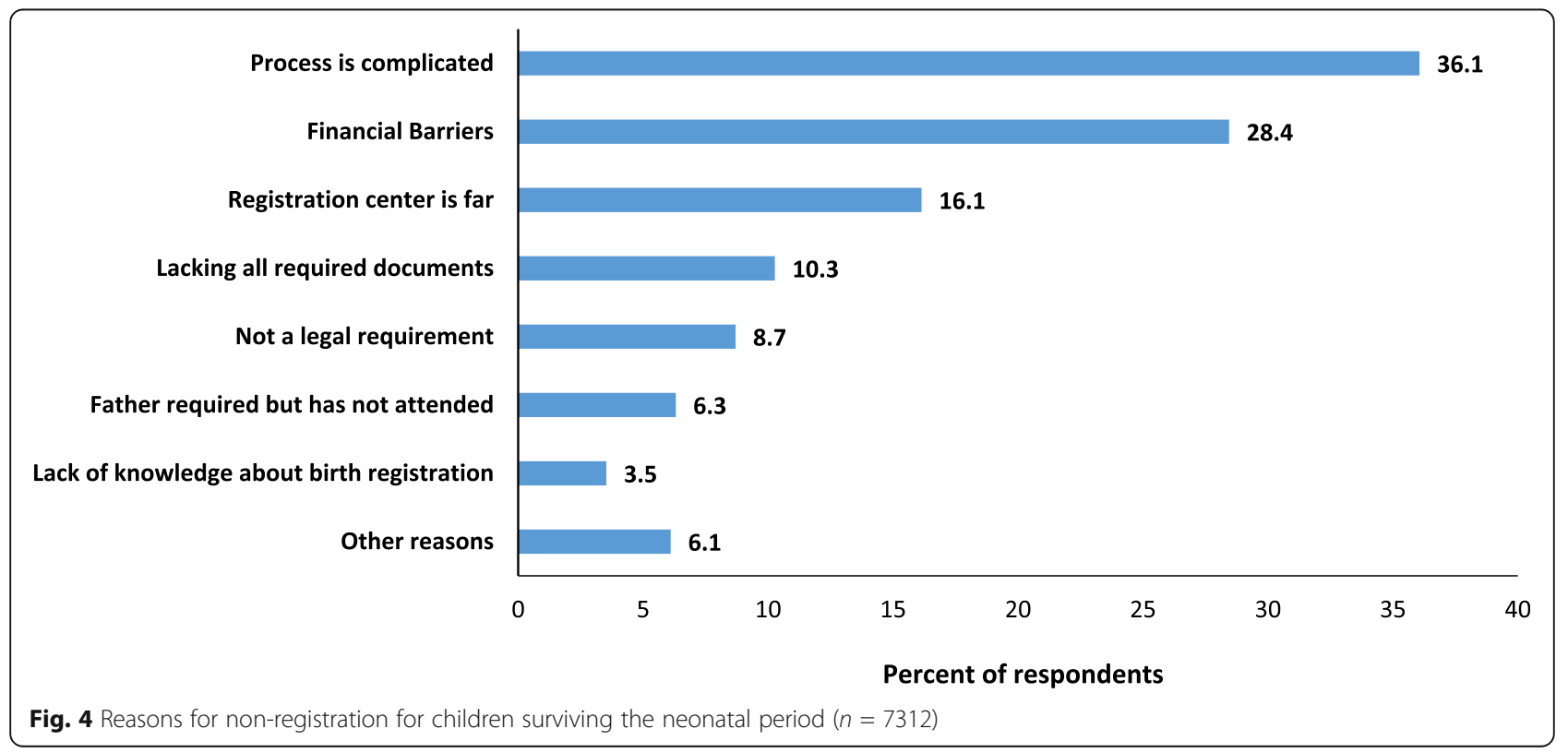




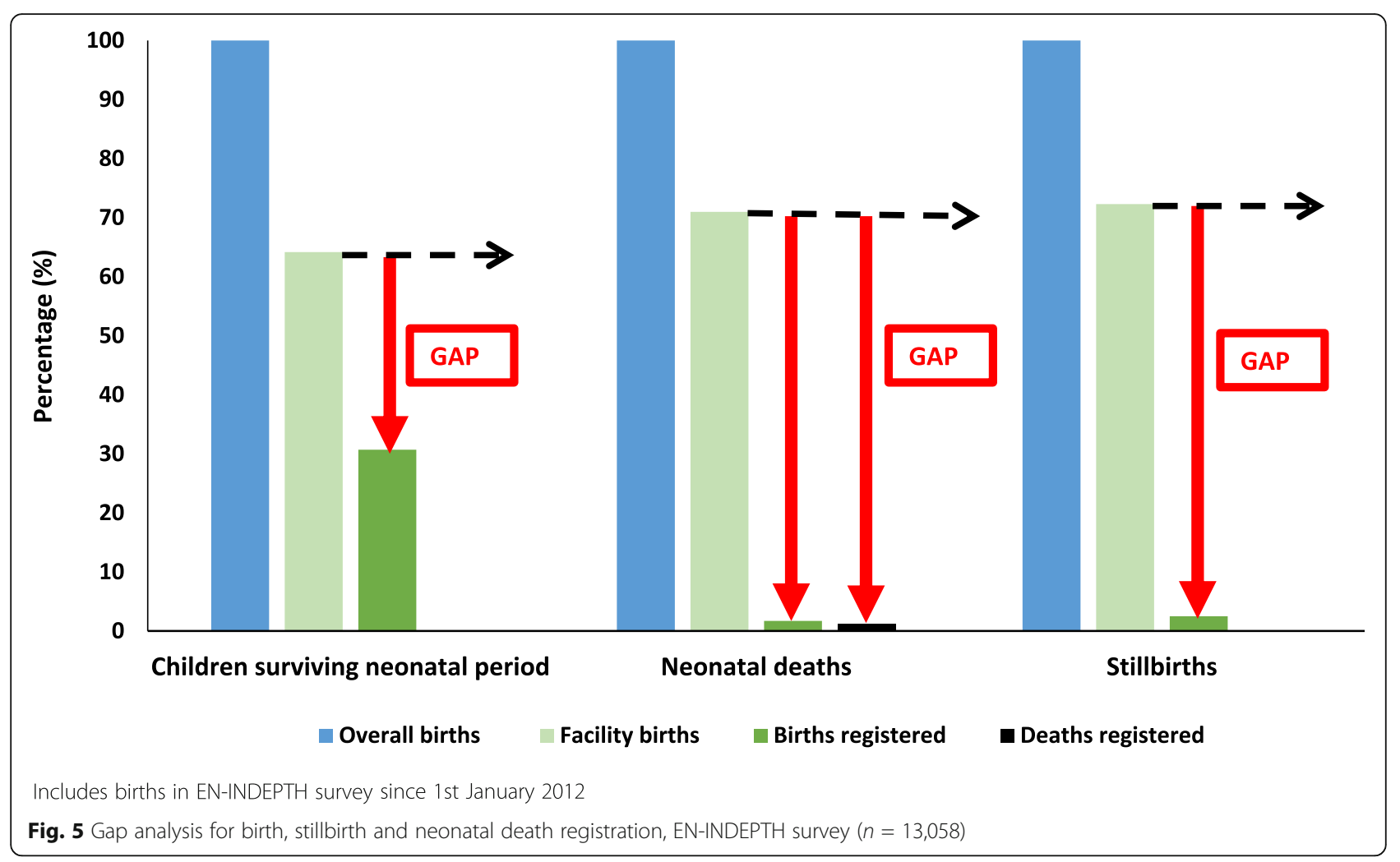

Whilst many LMICs are now working on strengthening CRVS, there are major variations between even these four countries (Table 1) [11]. In Uganda, Guinea-Bissau and Ethiopia, legislation regarding mandatory registration of births and deaths exists. However, enforcement of these laws is highly variable. Variation in the period within which to report occurrence of births and enforcement of regulation is one of the limiting factors for complete CRVS. In GuineaBissau, a birth is by law reported within 30 days, 90 days in Ethiopia and anytime in Uganda. Enforcing penalties on late registration of births is reported as a challenge in some countries such as Ethiopia and Ghana and where no penalties are legislated, like in Uganda, there are still reporting, registration and certification challenges of vital statistics [26].

Importantly, stillbirth and death registration is not included in either DHS or MICS standard questionnaires. Completeness of stillbirth and death registration has lagged behind birth registration, and whilst completeness has been assumed to be low, no previous estimates of completeness have been made using survey data [2] and indeed very few population-based studies have assessed completeness of stillbirth or death registration [27]. Our new questions were asked for 2510 stillbirths and neonatal deaths and were found to have high response rates.

We found a shockingly large gap for stillbirth registration. Currently, of the four countries included in this study, only Ghana has a legal provision for the registration of stillbirths (Table 1). Despite $72.9 \%$ of reported stillbirths occurring in facilities, only around $1 \%$ were reported to be registered in three sites, with $9.2 \%$ reported being registered in IgangaMayuge. In view of the lack of requirement for registration of stillbirths or a formal stillbirth or fetal death register in Guinea-Bissau, Ethiopia or Uganda, it is possible that women may have misunderstood the registration questions and reported 'registration' within the HDSS, e.g. when the pregnancy was 'registered', or some women may have misreported neonatal deaths (which could have been registered with the civil authority) as stillbirths, as misclassification between these events in surveys is relatively common [28, 29]. Whilst it is possible in Ghana that some of these stillbirths may have been notified directly to the civil registrar by the health providers for inclusion in the stillbirth or fetal death register as recommended by the United Nations Statistical Division [30], generally completeness of vital statistics for stillbirths in most LMICs is currently very low [31]. A revision of the laws in countries without provision for stillbirth registration is needed to require reporting of late gestation stillbirths, as a minimum, and investment in training and support to implement this legislation in accordance with United Nations guidelines [30]. Enabling registration of all facility stillbirths, with information on timing (antepartum/ intrapartum) and cause of death where feasible using the WHO Medical Certificate for Cause of Death, would greatly increase the availability of data to improve stillbirth estimates and tracking of progress towards ending preventable stillbirths 
$[13,32]$. Once these changes are in place, measuring completeness of stillbirth registration will require design and testing of survey questions that are stillbirth-specific.

The reported completeness of neonatal death registration in this study was even lower than for stillbirths (1.2\%), and consistent with the World Health Organization's estimate that fewer than $5 \%$ of neonatal deaths globally are registered [33]. A study undertaken in the urban Bandim site found that reported completeness of birth registration for neonatal deaths was much lower than for children surviving the neonatal period [11]. This presents a large gap in vital statistics for these babies which could be partly closed by improving facility-based notification of all births and mandating that both birth and death must be notified and recorded in the case of a neonatal death. Notifying every birth at the time of birth and building strong linkages between civil registration systems and health programmes could enable health programmes to identify live births eligible for services such as postnatal care and immunisation and to follow-up defaulters to identify children who have died and enable provision of care for surviving children. The introduction of local mechanisms for community health staff to serve as notifiers of stillbirths, neonatal and infant deaths could improve capture of these events when they occur outside facilities, as families have little incentive to register them.

Closing the gap for registration of facility births and also deaths around the time of birth, notably stillbirths, could address common reasons for non-registration and lead to large increases in completeness of birth, stillbirth and neonatal death registration in all sites. This is feasible to achieve. UNICEF, WHO and the Global Vaccine Alliance (Gavi) have provided successful examples for integrating CRVS and health systems, in particular immunisation systems, in recent reports including creating awareness of the importance of registration during antenatal and delivery care; ensuring all births and deaths occurring in health facilities are notified to the civil registrar, with death notification including cause of death; increasing the potential co-location of registration facilities within hospitals and other delivery facilities; notifying home births and deaths by community health workers; notifying unregistered children when presented for immunisation and other health services; promoting community outreach for creating demand for birth and death registration; and sensitising health workers on the importance of registration of births and deaths [3, 34-36]. However, if these strategies are to be successful, frontline health workers, managers and other stakeholders must be included in the design and roll out of systems to link health management information systems and CRVS [37]. In addition, further investment, training and resources are required to improve the classification and reporting of stillbirths and early neonatal deaths. These are required to reduce misclassification and ensure that comparable information is recorded for all these deaths in the vital statistics system, for example through health providers notifying all these events through a common notification system.

This study has strengths, notably being undertaken across four different settings in sub-Saharan Africa, including information on a large number of children (including 2510 stillbirths and neonatal deaths). However, we note that whilst women were able to provide plausible responses to these questions, we were unable to verify accuracy by comparing responses to actual birth or death registration records. Since this study was undertaken in HDSS sites amongst populations under surveillance, it is possible that this may affect women's responses, although in none of these sites are women routinely asked about birth or death registration of their children. Potential confusion between 'registration' with the HDSS, religious institutions or other groups and registration with the civil authorities, as highlighted in a UNICEF report [19], may have occurred, particularly with respect to stillbirth and death registration. The completeness of birth and death registration may therefore be even lower than we have estimated.

Reliable measures in surveys are crucial to track progress for birth and death registration. Surveys have the advantage of providing data that can be disaggregated by different categories such as place of residence, sex, maternal education, or socio-economic status to identify which children are being left behind. This study found that questions on both birth and death registration were feasible to ask in a household survey, with minimal additional time implications. Whilst asking birth registration questions for surviving children in the household or the child's questionnaire has the advantage of capturing information on all children regardless of whether the mother is in the household or eligible to be interviewed, children who are stillborn or who have died are missed. Asking additional questions on birth registration for nonsurviving children in the woman's questionnaire could provide information on deceased children who may be at higher risk of not being registered.

\section{Conclusions}

Given that around $80 \%$ of the world's births are now in facilities, closing the gap between facility birth and registration for these babies would increase birth and stillbirth registration completeness and enable timely tracking through routine facility data and annual vital statistics reports, instead of relying only on 5-yearly surveys. However, facility registration alone will leave behind $20 \%$ of all babies who are born outside facilities, who are often the poorest and at highest risk of stillbirth and neonatal mortality. Therefore, surveys remain crucial to track overall population-level progress for birth 
registration and to identify who is left behind in this marker for child rights.

There is a larger gap for death registration, with only $1.2 \%$ of neonatal deaths and $2.5 \%$ of stillbirths reported to be registered. More attention is required to capture these deaths in facility and community systems, count them through death certificates and improve cause of death data to count and end these deaths, which will be crucial for all governments if SDG targets are to be measured and met.

\section{Supplementary information}

Supplementary information accompanies this paper at https://doi.org/10. 1186/s12963-020-00231-2.

Additional file 1. Background overview of the four HDSS sites.

Additional file 2. Selection of women with a livebirth surviving the neonatal period.

Additional file 3. STROBE guidelines checklist.

Additional file 4. Additional results.

Additional file 5. Gap analysis for birth registration in EN-INDEPTH survey, by site.

Additional file 6. Ethical Approval of local Institutional Review Boards.

\section{Abbreviations}

CRVS: Civil registration and vital statistics; DHS: Demographic and health survey; EN-INDEPTH: Every Newborn-International Network for the Demographic Evaluation of Populations and their Health; FBH+: Full birth history (" + " denotes additional questions on pregnancy losses); FPH: Full pregnancy history; HDSS: Health and demographic surveillance system; LMIC: Low- and middle-income countries; MICS: Multiple Indicator Cluster Survey; SDG: Sustainable Development Goals

\section{Acknowledgements}

This supplement is dedicated to the memory of Professor Peter Byass, who was the Senior External Editor of the supplement. Peter died suddenly in August 2020 and will be greatly missed by the EN-INDEPTH study team and entire global health community.

We thank the 118 interviewers and many HDSS staff participating in this study for their hard work and dedication to this project. Many thanks to Samuelina Arthur, Claudia DaSilva, Olivia Nakisita and the relevant site staff for their administrative support.

We acknowledge the core funders for all sites/institutions.

We express appreciation to the EN-INDEPTH expert advisory group: Fred Arnold, Peter Byass, Trevor Croft, Kobus Herbst, Sunita Kishor, Florina Serbanescu, Turgay Unalan, Shane Khan and Attila Hancioglu.

Finally and most importantly, we thank the women participating in the ENINDEPTH study and their families, without whom this work would not have been possible.

The Every Newborn-INDEPTH Study Collaborative Author Group: Senior External Supplement Editor: Peter Byass; Stephen M Tollman; Hagos Godefay

Technical Supplement Editors: Joy Lawn; Peter Waiswa; Hannah Blencowe Managing Supplement Editors: Judith Yargawa; Joseph Akuze (data and statistics)

\section{Other EN-INDEPTH Collaborative Group Members:}

By team: PI followed by other members in alphabetical order

Bandim: Ane B Fisker (PI); Justiniano SD Martins; Amabelia Rodrigues; Sanne M Thysen

Dabat: Gashaw Andargie Biks (PI); Solomon Mokonnen Abebe; Tadesse Awoke Ayele; Telake Azale Bisetegn; Tadess Guadu Delele; Kassahun Alemu Gelaye; Bisrat Misganaw Geremew; Lemma Derseh Gezie; Tesfahun Melese; Mezgebu Yitayal Mengistu; Adane Kebede Tesega; Temesgen Azemeraw Yitayew
IgangaMayuge: Simon Kasasa (PI); Edward Galiwango; Collins Gyezaho; Judith Kaija; Dan Kajungu; Tryphena Nareeba; Davis Natukwatsa; Valerie Tusubira

Kintampo: Yeetey AK Enuameh (PI); Kwaku P Asante; Francis Dzabeng; Seeba Amenga Etego; Grace Manu; Alexander A Manu; Obed Ernest Nettey; Sam K Newton; Seth Owusu-Agyei; Charlotte Tawiah; Charles Zandoh

Matlab: Nurul Alam (PI); Nafisa Delwar; M Moinuddin Haider; Md. Ali Imam; Kaiser Mahmud

LSHTM/ Makerere School of Public Health: Angela Baschieri; Simon

Cousens; Vladimir Sergeevich Gordeev; Victoria Ponce Hardy; Doris Kwesiga; Kazuyo Machiyama

\section{Ethics and consent to participate}

The EN-INDEPTH study was granted ethical approval by the Institutional Review Boards in all operating countries as well as from Institutional Ethical Review Committee of the London School of Hygiene \& Tropical Medicine (Additional file 6). Respondents of every successful interview gave written consent/ascent after being informed of the objective, data use, procedure of the interview, risks and benefits of participating in the study, right to withdraw from interview anytime point of time and not responding to questions where she feels discomfort. The study ensured respondent's privacy at data collection and confidentiality at data use.

\section{About this supplement}

This article has been published as part of Population Health Metrics Volume 19 Supplement 1, 2021: Every Newborn-INDEPTH study: Improving the measurement of pregnancy outcomes in population-based surveys. The full contents of the supplement are available online at https://pophealthmetrics. biomedcentral.com/articles/supplements/volume-19-supplement-1.

\section{Authors' contributions}

The EN-INDEPTH study was conceptualised by JEL. All site teams contributed to the design of the study protocol and undertook data collection. SK, DN and DK with HB and JEL developed the detailed research questions and overall analysis plan for this paper. These were refined with inputs from the wider Every Newborn-INDEPTH study collaborator group including $A B$ at a multi-country workshop in Entebbe Uganda in February 2019. EG, TN, CG, ABF, MYM, FD and MMH implemented the study at the sites. CC and DJ were consulted specifically on birth, death and stillbirth registration questions and CRVS global context. JA prepared the survey data files. Analysis was undertaken by DN and HB. The manuscript was drafted by the IgangaMayuge team with $\mathrm{HB}$ and JEL; MMH and JY provided valuable comments. All authors reviewed and helped to revise the manuscript and reviewed and agreed the final version.

\section{Funding}

The EN-INDEPTH study (including publication costs) was funded by the Children's Investment Fund Foundation (CIFF) by means of a grant to LSHTM (PI Joy E. Lawn) and a sub-award to the INDEPTH MNCH working group with technical leadership by Makerere School of Public Health (PI Peter Waiswa).

\section{Availability of data and materials}

Data sharing and transfer agreements were jointly developed and signed by all collaborating partners. The datasets generated during the current study are deposited online at https://doi.org/10.17037/DATA.00001556 with data access subject to approval by collaborating parties.

\section{Consent for publication}

Not applicable.

\section{Competing interests}

The authors declare no competing interests.

\section{Author details}

${ }^{1}$ IgangaMayuge Health and Demographic Surveillance System, Makerere University Centre for Health and Population Research, Iganga, Uganda. ${ }^{2}$ Department of Epidemiology and Biostatistics, Makerere University School of Public Health, Kampala, Uganda. ${ }^{3}$ Makerere University Centre for Health and Population Research, Makerere, Uganda. ${ }^{4}$ Bandim Health Project, Bissau, Guinea-Bissau. ${ }^{5}$ Research Centre for Vitamins and Vaccines, Statens Serum 
Institut, Copenhagen, Denmark. ${ }^{6}$ Departmet of Clinical Research, Open Patient data Explorative Network (OPEN), University of Southern Denmark, Odense, Denmark. ${ }^{7}$ Dabat Research Centre Health and Demographic Surveillance System, Dabat, Ethiopia. ${ }^{8}$ Department of Health Systems and Policy, University of Gondar, Gondar, Ethiopia. ${ }^{9}$ Kintampo Health Research Centre, Kintampo, Ghana. ${ }^{10}$ Health Systems and Population Studies Division, icddr,b, Dhaka, Bangladesh. " 'Maternal, Adolescent, Reproductive \& Child Health (MARCH) Centre, London School of Hygiene \& Tropical Medicine, London, UK. ${ }^{12}$ Departent of Health Policy, Planning and Management, Makerere University School of Public Health, Kampala, Uganda. ${ }^{13}$ Centre of Excellence for Maternal Newborn and Child Health Research, Makerere University, Kampala, Uganda. ${ }^{14}$ United Nations Children's Fund (UNICEF), New York, USA. ${ }^{15}$ School of Public Health, University of the Western Cape, Cape Town, South Africa.

Published: 8 February 2021

\section{References}

1. United Nations: Convention on the rights of the child. 1989

2. Lawn JE, Blencowe H, Oza S, You D, Lee AC, Waiswa P, Lalli M, Bhutta Z, Barros AJ, Christian P, et al. Every newborn: progress, priorities, and potential beyond survival. Lancet. 2014;384:189-205.

3. United Nations Children's Fund: Birth registration for every child by 2030 : are we on track? 2019. https://data.unicef.org/resources/birth-registrationfor-every-child-by-2030/ [Accessed April 2020].

4. United Nations: Sustainable Development Goals 2015.

5. Every Woman Every Child: The global strategy for women's, children's and adolescents' health (2016-2030). 2015. https://www.everywomaneverychild org/wp-content/uploads/2017/10/EWEC_GSUpdate_Full_EN_2017_web-1. pdf [Accessed April 2020].

6. AbouZahr C, de Savigny D, Mikkelsen L, Setel PW, Lozano R, Nichols E, Notzon F, Lopez AD. Civil registration and vital statistics: progress in the data revolution for counting and accountability. The Lancet. 2015; 386:1373-85.

7. Cappa C, Gregson K, Wardlaw T, Bissell S. Birth registration: a child's passport to protection. Lancet Global Health. 2014;2(2):E67-E68.

8. Hunter W, Brill R. Documents, please. World Politics. 2016;68:191-228.

9. Hereward M, Williams C, Petrowski N, Cappa C. Universal birth registration by 2030: progress and challenges. Lancet. 2020;394:2211-2.

10. Bhatia A, Zanini Ferreira L, Barros A, Victora C. Who and where are the uncounted children? Inequalities in birth certificate coverage among childrne under five years in 94 countries using nationally representative household surveys. Int J Equity Health. 2017;16(1):148.

11. Baschieri A, Gordeev VS, Akuze J, Kwesiga D, Blencowe H, Cousens S, Waiswa P, Fisker AB, Thysen SM, Rodrigues A, et al. "Every Newborn-INDE PTH" (EN-INDEPTH) study protocol for a randomised comparison of household survey modules for measuring stillbirths and neonatal deaths in five health and demographic surveillance sites. J Glob Health. 2019;9: 010901

12. UN Inter-agency Group for Child Mortality Estimation: Child mortality estimates. 2019. https://childmortality.org/ [Accessed April 2020].

13. Lawn JE, Blencowe H, Waiswa P, Amouzou A, Mathers C, Hogan D, Flenady V, Froen JF, Qureshi ZU, Calderwood C, et al. Stillbirths: rates, risk factors, and acceleration towards 2030. Lancet. 2016;387:587-603.

14. United Nations Children's Fund. Is every child counted? Status of data for children in the SDGs. New York: United Nations Children's Fund; 2018.

15. Akuze J, Blencowe H, Waiswa P, Baschieri A, Gordeev VS, Kwesiga D, Fisker $A B$, Thysen SM, Rodrigues A, Biks GA, et al. Randomised comparison of two household survey modules for measuring stillbirths and neonatal deaths in five countries: the Every Newborn-INDEPTH study. Lancet Global Health. 2020;8:e555-66

16. World Bank. Survey Solutions CAPI/CAWI platform: Release 5.26. Washington DC: The World Bank; 2018

17. von Elm E, Altman DG, Egger M, Pocock SJ, Gøtzsche PC, Vandenbroucke JP. Strengthening the reporting of observational studies in epidemiology (STROBE) statement: guidelines for reporting observational studies. BMJ Global Health. 2007:335:806.

18. UNICEF. Birth registration for maternal newborn and child health: end of project report 2014-2019. New York: USA; 2019.

19. United Nations Children's Fund. Every child's birth right: Inequities and trends in birth registration. New York: United Nations Children's Fund; 2013.
20. Amo-Adjei J, Annim SK. Socioeconomic determinants of birth registration in Ghana. BMC Int Health Hum Rights. 2015;15:14.

21. Bhatia A, Krieger N, Beckfield J, Barros AJD, Victora C. Are inequities decreasing? Birth registration for children under five in low-income and middle-income countries, 1999-2016. BMJ Glob Health. 2019;4:e001926.

22. Dake FAA, Fuseini K. Registered or unregistered? Levels and differentials in registration and certification of births in Ghana. BMC Int Health Hum Rights. 2018;18:25.

23. Mohanty I, Gebremedhin TA. Maternal autonomy and birth registration in India: Who gets counted? PLoS One. 2018;13:e0194095.

24. Nomura M, Xangsayarath $P$, Takahashi K, Kamiya $Y$, Siengsounthone L, Ogino $H$, Kobayashi J. Socioeconomic determinants of accessibility to birth registration in Lao PDR. BMC Public Health. 2018;18:116.

25. Wodon Q, Yedan A. Obstacles to birth registration in Niger: estimates from a recent household survey. J Health Popul Nutr. 2019;38:26.

26. United Nations Children's Fund: CRVS profiles. 2018. https://data.unicef.org/ crvs/ [Accessed April 2020].

27. Lumbiganon P, Panamonta M, Laopaiboon M, Pothinam S, Patithat N. Why are Thai official perinatal and infant mortality rates so low? Int J Epidemiol. 1990;19:997-1000.

28. Christou A, Dibley MJ, Rasooly MH, Mubasher A, Hofiani SMS, Rashidi MK, Kelly PJ, Raynes-Greenow C. Understanding country-specific determinants of stillbirth using household surveys: the case of Afghanistan. Paediatr Perinat Epidemiol. 2019;33:28-44.

29. Liu L, Kalter HD, Chu Y, Kazmi N, Koffi AK, Amouzou A, Joos O, Munos M, Black RE. Understanding misclassification between neonatal deaths and stillbirths: empirical evidence from Malawi. PLoS One. 2016;11:e0168743.

30. United Nations Department of Economic and Social Affairs Statistical Division. Principles and recommendations for a vital statistics system. Statistical Papers; 2014. p. 19

31. Blencowe H, Cousens S, Jassir FB, Say L, Chou D, Mathers C, Hogan D, Shiekh S, Qureshi ZU, You D, Lawn JE. National, regional, and worldwide estimates of stillbirth rates in 2015, with trends from 2000: a systematic analysis. Lancet Glob Health. 2016;4:e98-e108.

32. World Health Organization: ICD-11 International Classification of Diseases for Mortality and Morbidity Statistics, Eleventh Revision, Reference Guide 2019. https://icd.who.int/icd11 refguide/en/index.html [Accessed April 2020].

33. World Health Organization: WHO mortality database. 2020. https://www. who.int/healthinfo/mortality_data/en/ [Accessed April 2020].

34. Correa G, Verstraete P, Soundardjee R, Shankar M, Paterson C, Hampton L, Jackson D, Muniz M, Mwamba R, Wenz K, et al. Immunization programmes and notifications of vital events. Bull World Health Organ. 2019;97:306-8.

35. Jackson D, Wenz K, Muniz M, Abouzahr C, Schmider A, Bratschi MW, Braschi MW, Kassam N, Diaz T, Mwamba R, et al. Civil registration and vital statistics in health systems. Bull World Health Organ. 2018;96:861-3.

36. Rahman $\mathrm{MH}, \mathrm{Cox} \mathrm{AB}$, Mills SL. A missed opportunity: birth registration coverage is lagging behind Bacillus Calmette-Guerin (BCG) immunization coverage and maternal health services utilization in low- and lower middleincome countries. J Health Popul Nutr. 2019;38:25.

37. Siagian C, Wandasari W, Sahputra F, Kusumaningrum S. Strategic yet delicate: the dilemma of involving health workers in facilitating birth registration in Indonesia. BMC Health Serv Res. 2019;19:889.

38. United Nations CHildren's Fund: CRVS profiles. 2018. https://data.unicef.org/ crvs/ [Accessed February 2020]

\section{Publisher's Note}

Springer Nature remains neutral with regard to jurisdictional claims in published maps and institutional affiliations. 